\title{
A PARTICIPAÇÃO DOS BRASILEIROS NO INSTITUTO INTERNACIONAL DE SOCIOLOGIA JURÍDICA DE OÑATI (1989- 2015)
}

\section{THE PARTICIPATION OF BRAZILIAN SCHOLARS IN THE INTERNATIONAL INSTITUTE FOR THE SOCIOLOGY OF LAW - OÑATI (1989-2015)}

\begin{abstract}
GERMANO SCHWARTZ
Doutor em Direito. Diretor Executivo Acadêmico da Escola de Direito da FMU (SP), onde leciona, também, no

Mestrado em Direito e Sociedade da Informação. Coordenador do Mestrado em Direito do Unilasalle/Canoas. Canoas, RS, Brasil. germano.schwartz@globo.com

Renata Almeida da Costa

Doutora em Direito pela Universidade do Vale do Rio dos Sinos (Unisinos). Professora do Mestrado em Direito do Centro Universitário La Salle (Unilasalle/Canoas). Canoas, RS, Brasil.
\end{abstract}

renata.costa@me.com

\begin{abstract}
RESUMO
O presente artigo tem como objetivo verificar a participação quantitativa dos brasileiros nas atividades típicas do Instituto Internacional de Sociologia Jurídica de Oñati, a partir de dados fornecidos pelo próprio Instituto, além do cruzamento desses com a base online de sua biblioteca. Nesse sentido, ainda, elabora cruzamento entre os alunos brasileiros do Mestrado em Sociologia Jurídica de Oñati e o impacto do Instituto em sua vida acadêmica, tomando por base os dados disponíveis na Plataforma Lattes. O corte temporal da análise abrange o período que compreende a inauguração do Instituto até o presente momento (2015). Ao final, apresentam-se considerações a respeito de quais atividades os brasileiros estão mais afeitos e sugerem-se ações para o desenvolvimento do recebimento de um maior número de estudantes e professores provenientes do Brasil.
\end{abstract}

Palavras-chave: Brasil; Brasileiros; Instituto Internacional de Sociologia Jurídica; Oñati; Sociologia Jurídica.

\begin{abstract}
The article seeks to verify the quantitative participation of Brazilians in the typical activities of the International Institute for the Sociology of Law in Oñati through the analysis of data provided by the Institute, as well as a cross-reference of this data with the Library's Online Database. In this sense, the article also crosses the references of Brazilians in the Oñati Master's Program and its impact in their academic life, using the information provided on the Lattes Curriculum Platform. The time frame of this analysis spans from the inauguration of the Institute up to the present time (2015). In the end, some comments are made in regards to which activities Brazilians are more inclined to participate in, and it also suggests actions that can be taken in order to receive a greater number of students and professors from Brazil.
\end{abstract}

Keywords: Brazil; Brazilians; International Institute for the Sociology of Law; Oñati; Sociology of Law. 


\section{SUMÁRIO}

INTRODUÇÃO; 1 OS BRASILEIROS NO INSTITUTO INTERNACIONAL DE SOCIOLOGIA JURÍDICA DE OÑATI; 1.1 O Mestrado em Sociologia Jurídica; 1.1.1 Atuação como Docentes; 1.1.2 Pós-Doutoramento; 1.1.3 Os Brasileiros enquanto Discentes do Mestrado; 1.2.1 Alunos regulares e eventuais; 1.2.2 O Perfil dos Alunos Eventuais; 1.2.3 O Perfil dos Alunos Regulares; 1.2.4 Estudantes com Tesina Eximia Cum Laude; 1.3 Organização de Workshops; 1.4 Publicações; 1.5 Bolsas; 1.5.1 Bolsa de Residência; 1.5.2 Pesquisadores e Professores Visitantes; 1.5.3 Bolsa Juan Celaya; 1.6 Biblioteca; 1.7 As Instâncias Diretivas: o Diretor Científico e o Patronato; CONCLUSÃO; REFERÊNCIAS.

\section{INTRODUÇÃO}

O Instituto Internacional de Sociologia Jurídica tem-se apresentado, durante seus quase trinta anos de existência, como o local de excelência desse ramo do saber para os pesquisadores do mundo inteiro. Localizado em uma pequena cidade (Oñati) da província de Gipuzkoa (Euskadi-Espanha), é fato que ele recebeu uma parcela de contribuição dos pesquisadores brasileiros na área da Sociologia Jurídica. 0 presente artigo intenta demonstrar de que maneira se deu tal participação nas atividades típicas do IISL (International Institute for the Sociology of Law).

Antes, porém, é preciso entender brevemente o momento único de sua criação. O IISL representa um esforço conjunto levado à consideração do País Vasco (Euskadi) pelo Research Committee on Sociology of Law (RCSL) da International Sociological Association (ISA). Criado em $1962^{1}$, durante o congresso de Washington da ISA, a primeira composição ${ }^{2}$ do RCSL tinha em sua composição Renato Treves (Presidente), Adam Podgorecki (Vice-Presidente) e Wilhem Aubert (Secretário), além de 18 membros no ato de sua fundação.

O RCSL tem como objetivo agrupar e organizar pessoas que abordavam a Sociologia do Direito $^{3}$ como tema central de suas pesquisas em nível mundial. Rapidamente, todavia, a ideia da criação de um Instituto Europeu de Sociologia ${ }^{4}$, o embrião - em termos de ideia - do IISL, tomou forma. Uma maneira de contraposição ao modelo da Law and Society norte-americana. Uma espécie de diferenciação funcional.

\footnotetext{
${ }^{1}$ PODGORECKI, Adam. The Changing Philosophy of the Research Committee of Sociology of Law (ISA). 1989. P. 12-29. PDF Oñati, p. 11

2 PODGORECKI, Adam. Goals of the RC12. 1996. P. 1-10. PDF Oñati, p. 1.

3 Ibidem. p. 1-2.

${ }^{4}$ Ibidem. p. 3.
} 
Tendo como grande impulsionador o polonês Adam Podgorecki, vencida a resistência da ISA em não abrir novos comitês, o RCSL empossou seu primeiro presidente o italiano Renato Treves. Desde 1962, até o final dos anos 80 do século passado, o RCSL tornou-se um verdadeiro "who is who" ${ }^{5}$ da Sociologia do Direito e seus objetivos iniciais foram modificados. Um deles, novamente, dizia respeito à criação de um centro que pudesse abrigar os pesquisadores em Sociologia do Direito. Por isso, Blankebur, Harriet e Gessner ${ }^{6}$, entre outros, propuseram encontrar um lugar quieto, reservado, onde pesquisadores pudessem fazer suas pesquisas, frequentarem meetings e escreverem livros: Oñati.

Conforme descrevem Arrese e Peréz-Perdomo ${ }^{7}$, na cerimônia de inauguração do IISL, em dezembro de 1988, Renato Treves, o primeiro presidente do RCSL, disse ter a expectativa de que o Instituto estabelecesse relações com os principais centros de estudo em Sociologia Jurídica do mundo. Pretendia que, de seus trabalhos, participassem professores jovens graduados provenientes dos mais diversos locais do globo. Nesse sentido, de acordo com essas aspirações, o artigo que ora se apresenta procura verificar, como já dito, de que maneira os brasileiros participaram do processo de consolidação do IISL, tudo isso segundo intenções anunciadas por Treves.

\section{OS BRASILEIROS NO INSTITUTO INTERNACIONAL DE SOCIOLOGIA JURÍDICA DE OÑATI}

Com base no que fora afirmado no item anterior, o artigo se desenvolve, agora, a partir das atividades para os quais o IISL fora criado. A partir delas, verificar-se-á de que maneira os brasileiros foram inseridos em tais atividades ou contribuíram, de alguma forma, para que o IISL se consolidasse.

Antes disso, todavia, gize-se a importância do IISL para a sociologia jurídica brasileira. Faria e Campilongo ${ }^{8}$ verificam que até os anos sessenta do século passado havia muita oferta de

\footnotetext{
${ }^{5}$ PODGORECKI, Adam. The Changing Philosophy of the Research Committee of Sociology of Law (ISA). 1989. P. 12-29. PDF Oñati, p. 8.

${ }^{6}$ PODGORECKI, Adam. Goals of the RC12. 1996. P. 1-10. PDF Oñati, p. 7.

${ }^{7}$ ARRESE MURGUZUR, S., PÉREZ-PERDOMO, R., forthcoming. El Máster de Sociología Jurídica de Oñati: la Percepción de los Graduados. Oñati Socio-legal Series [online], forthcoming. 2016. p. 2. Disponível em: <http://ssrn.com/abstract=2676532> Acesso em: 02 abr. 2017.

${ }^{8}$ FARIA, José Eduardo; CAMPILONGO, Celso Fernandes. A Sociologia Jurídica no Brasil. Porto Alegre: SAFE, 1991.
} 
A PARTICIPAÇÃO DOS BRASILEIROS NO INSTITUTO INTERNACIONAL DE SOCIOLOGIA JURÍDICA DE OÑATI (1989-2015)

trabalho para graduados em Direito no Brasil, tendo em vista a escassez de oferta de vagas na área em instituições de ensino no país. Com a Reforma Passarinho, de 1968, aumentou-se o número de vagas em Direito com um efeito colateral: formaram-se bacharéis técnicos sem uma formação humanista do fenômeno jurídico.

Nesse sentido, os autores ${ }^{9}$ rememoram que desde aquela época já se propugnava que o ensino do direito fosse reformador e renovador, isto é, que acompanhasse as necessidades de um espaço no tempo pautado por movimentos sociais com base em direitos coletivos e sociais. A questão era: como fazer isso? A alternativa defendida era a inclusão de disciplinas de caráter formador, como o caso da Filosofia do Direito, e, no âmbito do ensaio, a Sociologia Jurídica nos currículos de Direito do Brasil. O caminho não foi fácil, pois até a edição da Portaria 1886/1994 do MEC, a sociologia jurídica não era obrigatória nos Cursos de Direito brasileiros, à exceção da Universidade Federal de Santa Catarina.

A Portaria mencionada referia em seu artigo sexto, inciso I, que a sociologia (geral e jurídica) constituía-se em matéria que poderia ser distribuída em uma ou mais disciplinas do conteúdo mínimo dos cursos jurídicos no Brasil. A disposição foi repetida pela Resolução CNE/CES (Conselho Nacional de Educação - Câmara de Ensino Superior) 09/2004, em seu artigo quinto, inciso I. Essa última normativa ainda é vigente em solo brasileiro.

Com isso, é fato que a Sociologia Jurídica no Brasil experimentou grandes avanços, inclusive com a existência de uma Associação Brasileira de Pesquisadores em Sociologia do Direito (ABRASD). Contudo, antes das legislações citadas, os grandes problemas da área no Brasil diziam respeito à falta de grupos de pesquisa e de professores com formação na área. É especialmente nesse último quesito que o IISL teve importância para a sociologia jurídica brasileira $^{10}$, atuando como um farol e como um órgão em que se poderiam buscar as bases da formatação da disciplina.

É fato que a historiografia da sociologia jurídica no Brasil não inicia nos anos noventa do século passado, algo que remonta, por exemplo, a autores tais como Cláudio Souto e Pontes de Miranda, entre outros ${ }^{11}$. No entanto, a redemocratização brasileira, representada no âmbito do artigo pelas legislações em comento, proporcionou a formação de bacharéis em Direito com um

\footnotetext{
9 FARIA, José Eduardo; CAMPILONGO, Celso Fernandes. A Sociologia Jurídica no Brasil. Porto Alegre: SAFE, 1991.

${ }_{10}$ Ibidem.

11 SOUTO, Cláudio. Sobre a Pesquisa Científica em Direito. Revista Brasileira de Sociologia do Direito, v.1, n.1, 2014, p. 38-40. Disponível em: <http://dx.doi.org/10.21910/rbsd.v1n1.2014.35> Acesso em: 03 abr. 2017.
} 
maior traço humanista. Ela é coincidente com a criação do IISL, nos anos de 1988 e 1989. Essa similaridade histórica é outro fator para que o Instituto se tornasse tão influente na sociologia jurídica brasileira, fato lembrado por José Ribas Vieira em depoimento dado a Fragale Filho e Joaquim Alvim, no qual ele refere a centralidade de Oñati na construção de um pensamento crítico a respeito do Direito no Brasil:

Aquele início dos anos 80 foi a Anpocs e tal... Então, no início dos anos 90 , foi Oñati, que Miaille não participava, mas participava o Arnaud. O Arnaud fez tudo pela gente. 0 Arnaud fez tudo pela gente naquele início dos anos 90 . E foi graças ao Arnaud, que pediu a mim, que aí eu fui ao Lima para traduzir aquele livro que custava à época... o Lima bancou doze mil reais, que eram mais ou menos doze mil dólares, quer dizer, a equiparação... ${ }^{12}$

Fragale Filho e Joaquim Alvim recordam que também no âmbito das publicações o IISL auxiliou no desenvolvimento da sociologia jurídica brasileira:

Com efeito, em 1991, o Onãti International Institute for the Sociology of Law (IISL), criado por André-Jean Arnaud, publica, na série Onãti proceedings, um volume sob a coordenação de Oscar Correas dedicado à sociologia jurídica na América Latina, no qual figuram textos de Wanda de Lemos Capeller, José Ribas Vieira, José Eduardo Faria e Celso Fernandes Campilongo, todos com intensa participação nas atividades do grupo "Direito e Sociedade" da Anpocs. ${ }^{13}$

Verifica-se, portanto, que o IISL e a sociologia jurídica brasileira possuem um momento temporal específico coincidente - o fim dos anos 80 e o início dos anos 90 do século passado. Não é sem razão, pois havia, também, uma comunhão de objetivos ${ }^{14}$ entre a pesquisa brasileira na área e os propósitos do Instituto. Nessa esteira, o Mestrado em Sociologia Jurídica do IISL foi um caminho natural dos pesquisadores brasileiros ligados ao tema. A participação tupiniquim em tal curso é analisada a seguir.

\subsection{Mestrado em Sociologia Jurídica}

O Mestrado em Sociologia Jurídica de Oñati consiste num curso reconhecido pela Universidade do País Vasco (Espanha) e que se realiza durante um período de doze meses.

\footnotetext{
${ }^{12}$ FRAGALE FILHO, Roberto; ALVIM, Joaquim Leonel de Rezende. O Movimento "Critique du Droit"e seu Impacto no Brasil. Revista Direito GV, v.3, n.2, jul-dez 2007, p. 139-164. Disponível em: <http://bibliotecadigital.fgv.br/ojs/index.php/revdireitogv/article/view/35186/33990> Acesso em: 03 abr. 2017.

${ }^{13}$ Ibidem.

14 JUNQUEIRA, Eliane Botelho; OLIVEIRA, Luciano (Org). Ou Isto ou Aquilo: a sociologia jurídica nas Faculdades de Direito. Rio de Janeiro: Letra Capital, 2002.
} 
Ofertado, regularmente, desde 1990, é considerado de excelência. Sua língua é o Inglês e, ao final, o aluno terá cursado 60 créditos ECTS (Sistema Europeu de Transferência de Créditos) e escrito uma dissertação supervisionada e avaliada por docentes ligados ao Curso.

Registre-se que sua grade varia anualmente, com aprovação do Patronato do IISL, tendo em vista a necessidade de atualização dos temas relativos à conexão Direito e Sociedade. São professores do curso expoentes da Sociologia Jurídica, reconhecidos mundialmente, como, entre outros: André-Jean Arnaud, Alessandro Baratta, Roger Coterrel, Vincenzo Ferrari, Alberto Febbrajo, Volkmar Gessner, David Nelken e Gunther Teubner.

\subsubsection{Atuação como Docentes}

Para lecionar no IISL, é preciso que o docente se candidate à vaga de docência, que proponha um curso específico na área da Sociologia Jurídica e que domine a língua inglesa, pois o Inglês é o idioma utilizado pelos alunos e pelos professores durante o Curso, inclusive em sua parte escrita. Cada turma do Mestrado tem, em média, 13 disciplinas.

O Curso ocorre de modo anual desde 1990, sendo 25 turmas até o presente momento. Acaso se use o critério de um docente por disciplina (algumas vezes, as aulas são compartilhadas por mais de um professor), o número de professores superaria o de 200. Contudo, o número correto é o de 189 docentes, fato justificável, pois é comum que um mesmo professor atue em mais de um ano em função de seu bom desempenho.

O que chama a atenção é o pouco número de professores brasileiros no Mestrado do IISL, fato que contrasta com a participação dos discentes. São três os docentes, representando o índice de $1,58 \%$ do total de professores que atuaram no Curso. Ei-los:

a) Wanda Capeller (1990/1991) - Official and Unofficial Justice.

b) Wanda Capeller (1991/1992) - Penal Regulation in Contemporary European Societies.

c) Wanda Capeller (1993/1994) - Cross-Boarder Illegal Interaction.

d) Germano Schwartz (2014/2015) - Socio-Legal Approaches to New Social Movements.

e) lage Zendron Miola (2015/2016) - Sociology of Law and the Economy (compartilhada com o Professor Sol Piccioto)

Observa-se um hiato muito grande entre o primeiro e o segundo professor. As razões podem ser várias, como, por exemplo, o fato de que o docente não recebe remuneração para lecionar, exceto hospedagem, passagens e ajuda de custo (diárias). Também é fato que o timing 
do Curso (setembro-março) é desfavorável para os professores brasileiros, que teriam de usar suas férias (janeiro e/ou fevereiro) para trabalharem no IISL. Entretanto, o domínio do idioma Inglês parece ser a maior dificuldade.

\subsubsection{Pós-Doutoramento}

O estágio pós-doutoral não se apresenta como um título acadêmico. Como o seu próprio nome diz, trata-se de um período em que o doutor se dedica a uma atividade de pesquisa específica. De acordo com o CNPQ, na RN 029/2012, seu objetivo é o de: “possibilitar ao pesquisador a capacitação e atualização de seus conhecimentos por meio de estágio e desenvolvimento de projeto com conteúdo científico ou tecnológico inovador, em instituição no exterior ou no Brasil".

A diferença fundamental com relação ao sistema europeu, em que o IISL se encaixa, é que, naquele continente, o pós-doutorado é considerado um emprego, enquanto no Brasil, muito embora seja uma política da CAPES e das Instituições Universitárias de se exigi-lo e valorá-lo cada vez mais, ele se trata de uma etapa de amadurecimento científico. Levando isso em consideração, o IISL, a partir da gestão do Prof. Adam Czarnota (2013-2016), iniciou a política de pós-doutoramento. Nesse sentido, uma brasileira, a Professora Renata Almeida da Costa, realizou seu pós-doutorado no IISL no ano de 2015. Trata-se da única pesquisadora, até o presente momento, a desenvolver tal atividade em Oñati.

\subsubsection{Os Brasileiros enquanto Discentes do Mestrado}

Uma das participações mais importantes dos brasileiros no IISL é dada na condição de discente do Mestrado. A análise a seguir se debruça sobre essa situação e procura apontar perfis e argumentos a respeito de dita inserção.

\subsubsection{Alunos regulares e eventuais}

A lista dos estudantes brasileiros que frequentaram o Mestrado em Sociologia Jurídica do IISL é encontrada em seu website. Eles são classificados como alunos regulares, isto é, 
aqueles que completaram o Mestrado, e como alunos eventuais, ou seja, discentes que assistiram a um ou mais cursos componentes da grade curricular do curso em comento.

O número total de brasileiros em ambas as categorias é de 19 (dezenove). Doze deles são/foram alunos regulares (Tiago de García Nunes, Fernanda Galizia Noriega, Fernando Maldonado Goya, Mariana Kiefer Kruchin, Gustavo Pereira Farah, Nuria Pérez Bertachini, Lucas Pizzolatto Konzen, Charles Pontes Gomes, Anatercia Rovani, lagê Zendron Miola e Ana Márcia Souza (astro). Desse número, onze já concluíram o Mestrado, e um aluno foi admitido para a turma 2016/2017 (Alexandre Brandão). Na mesma linha, sete brasileiros são classificados como discentes eventuais.

Com isso, tem-se que, dos estudantes brasileiros no Mestrado do IISL, 63,15\% são/foram regulares e $36,85 \%$ foram eventuais, o que pode ser representado pelo gráfico abaixo:

Figura 1 - Gráfico demonstrando a proporção de estudantes regulares e estudantes eventuais.

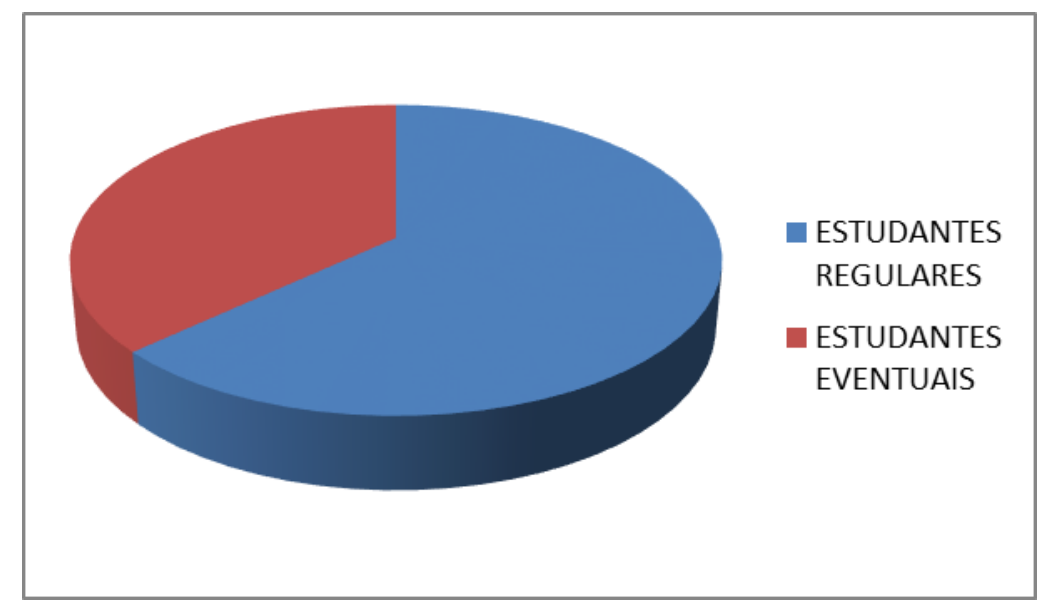

Observa-se, portanto, que a preferência dos brasileiros em relação ao Mestrado é por fazê-lo de modo integral, muito embora não se possa deixar de dizer que uma boa parte deles prefere a modalidade eventual.

Nesse sentido, importantes observações são trazidas por Arrese e Perez-Perdomo sobre a procedência $^{15}$ dos egressos do Mestrado em Sociologia Jurídica do IISL.

\footnotetext{
${ }^{15}$ ARRESE MURGUZUR, Susana; PÉREZ-PERDOMO, Rogelio. El Máster de Sociología Jurídica de Oñati: la Percepción de los Graduados (The Oñati Master on Sociology of Law: the Alumnae's Perception). Oñati Socio-Legal Series, Vol. 6, No. 3, 2016. Disponível em: <http://ssrn.com/abstract=2676532> Acesso em 03 abr. 2017.
} 
Figura 2 - Tabela que demonstra a origem dos estudantes regulares.

\begin{tabular}{ccc}
\hline REGIÃO & QUANTIDADE & PERCENTAGEM \\
\hline Ásia & 23 & 7,96 \\
África & 18 & 6,23 \\
Europa (sem a Espanha) & 79 & 27,33 \\
Espanha & 46 & 15,92 \\
América Latina & 85 & 29,41 \\
Estados Unidos e Canadá & 38 & 13,15 \\
\hline TOTAL & 289 & 100,00 \\
\hline
\end{tabular}

De acordo com a tabela e com os autores retrorreferidos, verifica-se que a América Latina contribuiu com o maior número de estudantes regulares do Mestrado, sendo os mais importantes, na ordem: Argentina (19), México (16), Colômbia (14) e Brasil (11).

Com base nessas observações, pode-se chegar a outras. A saber: a) 0 Brasil contribui com 3,89\% dos egressos do Curso em análise; b) 0 Brasil representa $12,94 \%$ dos estudantes provenientes da América Latina. É grande - e de monta -, pois, a participação dos brasileiros enquanto discentes no Mestrado em Sociologia Jurídica do IISL. Necessário, contudo, aprofundar um pouco mais tais dados.

\subsubsection{O Perfil dos Alunos Eventuais}

Os alunos eventuais diferem dos alunos regulares substancialmente. A partir da coleta dos dados constantes da plataforma Lattes com as informações obtidas juntas ao IISL, é possível chegar aos dados que seguem. 


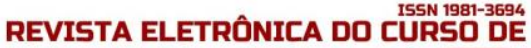

Figura 3 - Tabela com informações a respeito dos alunos eventuais.

\begin{tabular}{|c|c|c|c|c|c|}
\hline ALUNO & $\begin{array}{l}\text { TURMA DO } \\
\text { MESTRADO }\end{array}$ & $\begin{array}{l}\text { TITULAÇÃO } \\
\text { PRÉVIA AO } \\
\text { CURSO } \\
\text { EVENTUAL }\end{array}$ & $\begin{array}{l}\text { ATUAČ̃̃O } \\
\text { ACADÊMICA }\end{array}$ & $\begin{array}{l}\text { TITULAÇÃO } \\
\text { POSTERIOR AO } \\
\text { CURSO EVENTUAL }\end{array}$ & $\begin{array}{l}\text { UNIDADE DA } \\
\text { FEDERAÇÃO }\end{array}$ \\
\hline Cláudia Albagli & $2013-2014$ & SEM DADOS & SEM DADOS & SEM DADOS & SEM DADOS \\
\hline $\begin{array}{l}\text { Renata Almeida } \\
\text { da Costa }\end{array}$ & $2006-2007$ & Doutora & $\begin{array}{l}\text { Professora em } \\
\text { Graduação e } \\
\text { Mestrado em IES } \\
\text { brasileiras }\end{array}$ & Doutora & RS \\
\hline Carolina Alvarez & $2012-2013$ & SEM DADOS & SEM DADOS & SEM DADOS & SEM DADOS \\
\hline $\begin{array}{l}\text { Elida de Oliveira } \\
\text { Lauris dos } \\
\text { Santos }\end{array}$ & $2006-2007$ & Doutoranda & $\begin{array}{l}\text { Pesquisadora do } \\
\text { CES-Coimbra }\end{array}$ & Doutoranda & PA \\
\hline $\begin{array}{l}\text { Paula Gil } \\
\text { Larruscahim }\end{array}$ & $2012-2013$ & Mestre & $\begin{array}{l}\text { Professora em } \\
\text { Graduação em } \\
\text { IES Brasileira }\end{array}$ & $\begin{array}{l}\text { Doutoranda/Bolsista } \\
\text { Erasmus Mundus }\end{array}$ & RS \\
\hline Cora Hagino & $2010-2011$ & Doutoranda & $\begin{array}{l}\text { Professora em } \\
\text { Graduação e } \\
\text { Mestrado em IES } \\
\text { brasileiras }\end{array}$ & Doutoranda & RJ \\
\hline $\begin{array}{l}\text { Augusto Jobim } \\
\text { do Amaral }\end{array}$ & $2006-2007$ & Mestre & $\begin{array}{l}\text { Professor em } \\
\text { Graduação de } \\
\text { IES brasileiras. }\end{array}$ & Doutor & RS \\
\hline
\end{tabular}

A tabela demonstra que:

a) Muito embora o Mestrado exista desde 1990, os alunos brasileiros em caráter eventual só começam a se matricular em 2006/2007, ano com maior tendência. Outro fluxo importante se dá depois do ano de 2010, coincidentemente época em que a economia brasileira se encontrava em um bom período e no qual a taxa de conversão do euro para o real era, ao menos, razoável. Essa pode ser uma razão para explicar o fenômeno. Outra é a de que os cursos ofertados e os docentes que neles lecionaram, nos períodos citados, podem ter interessado mais aos brasileiros.

b) A maioria dos alunos dessa modalidade provém do Brasil, do estado do Rio Grande do Sul.

c) Trata-se, em maioria, de profissionais já estabelecidos e colocados no mundo acadêmico. Não procuraram o IISL para sua formação acadêmica, e sim, para seu aperfeiçoamento.

d) Em vista da titulação anterior e posterior ao Curso eventual, pode-se deduzir que o período no Mestrado corresponde a um tema específico de alto interesse nas pesquisas que o 
aluno conduzia à época. Na linguagem de Arrese e Perez-Perdomo, os estudantes dessa categoria são "generalmente atraídos por una asignatura específica y/o el prestigio del profesor."16

Como já referido alhures, esse perfil não é o mesmo dos alunos regulares como se verá a seguir.

\subsubsection{O Perfil dos Alunos Regulares}

Os alunos regulares somam o número de doze conforme já dito e possuem o seguinte perfil, todos eles obtidos a partir das informações existentes na Plataforma Lattes:

Figura 4 - Tabela com informações a respeito dos alunos regulares.

\begin{tabular}{|c|c|c|c|}
\hline NOME ALUNO & TURMA & ATUAÇÃO PÓS-MESTRADO & UNIDADE DA FEDERAÇÃO \\
\hline Charles Pontes & $1995 / 1996$ & $\begin{array}{l}\text { Doutorado em Ciência Política } \\
\text { (SBI/IUPERJ). Pesquisador da } \\
\text { Fundação Casa Rui Barbosa. }\end{array}$ & RJ \\
\hline Tiago de García Nunes & $2006 / 2007$ & $\begin{array}{l}\text { Professor nos Cursos de Direito } \\
\text { da UCPEL. Doutorando no } \\
\text { Programa em Sociologia e } \\
\text { Direito da UFF. }\end{array}$ & RS \\
\hline Fernanda Galizia Noriega & $1994 / 1995$ & $\begin{array}{l}\text { Juíza de Direito. Doutora em } \\
\text { Direito. }\end{array}$ & SP \\
\hline Fernando Goya Maldonado & $2009 / 2010$ & $\begin{array}{l}\text { Doutorando em Democracia no } \\
\text { Século XXI (Coimbra) } \\
\text { Assessor Jurídico na Prefeitura } \\
\text { de Canoas }\end{array}$ & RS \\
\hline Mariana Kiefer Kruchin & $2009 / 2010$ & Advogada. & SP \\
\hline Gustavo Pereira Farah & $1999 / 2000$ & Doutor em Direito & PR \\
\hline Nuria Pérez Bertachini & $2004 / 2005$ & Advogada e Tradutora. & MG \\
\hline Lucas Pizzolato Konzen & $2008 / 2009$ & 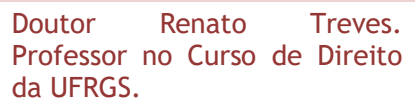 & RS \\
\hline Anatercia Rovani & $2008 / 2009$ & Doutoranda Renato Treves & RS \\
\hline lage Zendron Miola & $2008 / 2009$ & $\begin{array}{l}\text { Doutor Renato } \quad \text { Treves. } \\
\text { Professor na Faculdade Direito } \\
\text { de Itu }\end{array}$ & RS \\
\hline Alexandre Brandão & $2016 / 2017$ & Advogado & RS \\
\hline Ana Marcia & 1998/1999 & $\begin{array}{l}\text { Reside em Oñati. Não seguiu } \\
\text { carreira acadêmica. }\end{array}$ & \\
\hline
\end{tabular}

16 ARRESE MURGUZUR, Susana; PÉREZ-PERDOMO, Rogelio. El Máster de Sociología Jurídica de Oñati: la Percepción de los Graduados (The Oñati Master on Sociology of Law: the Alumnae's Perception). Oñati Socio-Legal Series, Vol. 6, No. 3, 2016. Disponível em: <http://ssrn.com/abstract=2676532> Acesso em 03 abr. 2017. 
A análise da tabela traz alguns dados pertinentes. Vejam-se:

a) Existe uma boa distribuição, em décadas, de alunos regulares brasileiros no Mestrado;

b) 0 Mestrado é utilizado como o primeiro passo da formação acadêmica para uma significativa parte dos brasileiros regulares $(83,33 \%)$ que, depois, cursam o Doutorado;

c) Apenas dois alunos brasileiros dessa categoria não partiram para o Doutorado $(16,67 \%)$

d) Somente quatro ex-alunos regulares (33\%), até agora, estão inseridos no mercado de trabalho como professores;

e) Dois discentes atuam em órgãos da Administração Pública $(16,66 \%)$, uma como magistrada e o outro como assessor jurídico (8,33\%);

f) Chama a atenção o fato de que $50 \%$ dos alunos regulares são provenientes do Estado do Rio Grande do Sul, uma tendência semelhante com a dos alunos eventuais.

Desse modo, tem-se que o Mestrado em Sociologia Jurídica de Oñati, para os alunos regulares brasileiros, apresenta como foco principal sua formação acadêmica stricto sensu, destinada, basicamente, ao desenvolvimento de uma carreira acadêmica (professor e pesquisador) e, secundariamente, à Administração Pública do Brasil.

\subsubsection{Estudantes com Tesina Eximia Cum Laude}

Uma tesina, isto é, uma pequena tese, ou, no equivalente brasileiro, dissertação, é defendida por todos os alunos do Mestrado ao final do Curso. As melhores recebem uma Eximia Cum Laude ${ }^{17}$. Apenas trinta e quatro delas receberam tal galhardia. Dessas, duas são provenientes do Brasil e ambas escritas por autores originários do Estado do Rio Grande do Sul. São elas:

a) Tiago de García Nunes: Porto Alegre-Brasil, Da Cidade "Legal” A Cidade "Real": A Produçao Informal de Um Assentamento Urbano e Sua Regularizaçao Fundiária".

b) Lucas Pizzolato Konzen: Postcards of Exclusion and Places off the Map: a sociolegal case study of urban public spaces in Donostia - San Sebastián.

\footnotetext{
${ }_{17}$ ARRESE MURGUZUR, Susana; PÉREZ-PERDOMO, Rogelio. El Máster de Sociología Jurídica de Oñati: la Percepción de los Graduados (The Oñati Master on Sociology of Law: the Alumnae's Perception). Oñati Socio-Legal Series, Vol. 6, No. 3, 2016. Disponível em: <http://ssrn.com/abstract=2676532> Acesso em 03 abr. 2017.
} 


\subsection{Organização de Workshops}

Os workshops são parte integrante da vida do IISL. Destinam-se a fomentar um dos objetivos maiores do Instituto: tornar-se o local de atração de pesquisadores na área da Sociologia Jurídica, bem como produzir conhecimento sobre a área, a partir das sessões realizadas. Dessa maneira, o IISL oferece acomodação, transporte de Bilbao e/ou das adjacências até Oñati, organização e salas para o evento, além de almoço para os organizadores e participantes dos workshops aprovados. Realizados durante as férias do Curso de Mestrado, o número de propostas supera, via de regra, as datas disponíveis para sua realização.

Nessa linha de raciocínio, a tabela abaixo demonstra a participação dos brasileiros enquanto organizadores/propositores dos workshops:

Figura 5 - Tabela com informações a respeito da participação de brasileiros nos workshops.

\begin{tabular}{|c|c|c|c|}
\hline ANO & DATA & TÍTULO & ORGANIZADOR (ES) \\
\hline 1991 & $02 / 07$ & $\begin{array}{l}\text { The Implementation of Equal } \\
\text { Rights for Women and Men }\end{array}$ & Fanny Tabak \\
\hline 1993 & $10-12 / 02$ & Democratization of Justice & $\begin{array}{l}\text { José Ribas Vieira } \\
\text { Eliane B. Junqueira }\end{array}$ \\
\hline 1993 & $05-09 / 07$ & $\begin{array}{l}\text { Women's Rights: legal } \\
\text { achievements and their } \\
\text { limitations. }\end{array}$ & Fanny Tabak \\
\hline 1996 & $20-21 / 06$ & $\begin{array}{l}\text { New Alternatives for Old } \\
\text { Challenges: women's }\end{array}$ & Fanny Tabak \\
\hline 1999 & $12-13 / 07$ & $\begin{array}{l}\text { Legislación Ambiental: } \\
\text { formulaciõn, intereses y } \\
\text { processos de implementación }\end{array}$ & $\begin{array}{c}\text { Anamaria Vaz de Assis Medina } \\
\text { José } M^{a} F . \text { Medina }\end{array}$ \\
\hline 2000 & $7-9 / 06$ & $\begin{array}{c}\text { The Role of Comunnitarian } \\
\text { Law in Inplementing Equal } \\
\text { Rights }\end{array}$ & Fanny Tabak \\
\hline 2002 & $15-16 / 07$ & $\begin{array}{l}\text { Políticas Neoliberales y } \\
\text { Derechos Fundamentales }\end{array}$ & $\begin{array}{l}\text { Jacinto Nelson de Miranda } \\
\text { Coutinho }\end{array}$ \\
\hline 2010 & $15-16 / 7$ & $\begin{array}{c}\text { Socio-Legal Perspectives on } \\
\text { the Ajudication of } \\
\text { International Economic } \\
\text { Disputes }\end{array}$ & $\begin{array}{c}\text { Sol Picciotto } \\
\text { José Augusto Fontoura }\end{array}$ \\
\hline 2014 & $10-11 / 7$ & $\begin{array}{l}\text { Sociolegal Aspects of the } \\
\text { Creative Economy }\end{array}$ & $\begin{array}{c}\text { José Augusto Fontoura Costa } \\
\text { Marcos Wachowicz }\end{array}$ \\
\hline 2006 & $1-2 / 06$ & $\begin{array}{c}\text { Sistemas Punitivos en } \\
\text { America Latina: } \\
\text { perspectiva transdisciplinar }\end{array}$ & $\begin{array}{l}\text { María Palma Wolff } \\
\text { Salo de Carvalho }\end{array}$ \\
\hline 2015 & $10-11 / 09$ & $\begin{array}{l}\text { (dis)Order and } \\
\text { (des)Integration: The Role } \\
\text { of Law facing the new } \\
\text { Social Movements }\end{array}$ & $\begin{array}{l}\text { Germano Schwartz } \\
\text { Salo de Carvalho }\end{array}$ \\
\hline
\end{tabular}


Consideráveis observações podem ser constatadas a partir da análise do quadro em questão. Assim:

a) Essa não é uma atividade em que a predominância dos organizadores seja proveniente do Rio Grande do Sul. Ela é bem distribuída nacionalmente, muito embora os dois últimos aprovados sejam oriundos daquele Estado, talvez a demonstrar alguma tendência de conexão entre os assuntos por ele discutidos e as prioridades do IISL, entre elas, o interesse da temática para o País Vasco.

b) Existe certa repetição de nomes entre os organizadores dos workhops. Fanny Tabak organizou quatro deles e Salo de Carvalho, dois.

c) As temáticas da década de noventa do século passado estão bastante ligadas à consolidação da democracia no Brasil, em especial a questão da igualdade, enquanto as do novo milênio não se prendem tanto às questões de cidadania quanto às de aspectos sociológicos de aplicação e de efetivação da legislação.

d) A organização de workshops em espanhol é relevante, sendo dois. Eles normalmente são realizados por autores de língua espanhola, o que não é o caso dos brasileiros. Novamente, o Inglês, aqui, desponta como uma barreira a ser vencida.

\subsection{Publicações}

O IISL, seguindo seu escopo de produzir conhecimento em Sociologia Jurídica, possui uma série de atividades ligadas a publicações. Basicamente, são duas: (a) série de livros relacionados aos workshops, ao Mestrado ou a eventos organizados pelo Instituto; (b) revistas científicas.

Na primeira categoria, os livros relacionados aos workshops fazem parte, em Inglês, da Oñati Working Papers, editada pelo próprio Instituto, e da Oñati International Series in Law and Society, editada pela Hart; e, em Espanhol, da Derecho y Sociedad, publicada pela Dickynson. Da análise, um dado para o qual se deve atentar é que dos dez workshops já realizados por brasileiros, apenas um ${ }^{18}$ resultou em publicação. Isso demonstra que o uso dessa modalidade, ao menos para os brasileiros, está centrada na discussão do conhecimento e não em sua produção.

${ }^{18}$ TABAK, Fanny (Ed). The Implementation of Equal Rights for Men and Women. Oñati Proceedings. Institute International for the Sociology of Law: Oñati, 1991. 
A PARTICIPAÇÃO DOS BRASILEIROS NO INSTITUTO INTERNACIONAL DE SOCIOLOGIA JURÍDICA DE OÑATI (1989-2015)

A série de livros que diz respeito aos eventos e outras ações é a Oñati Proceedings. Nela, novamente, não há a presença de brasileiros como organizadores, o que se justifica pelo fato de ser essa atividade realizada pelo próprio IISL, sendo natural, portanto, que a organização caiba, exclusivamente, ao Instituto.

Para os trabalhos provenientes do Mestrado, editaram-se a Oñati Working Papers e a Oñati Master Tesinas. Nessa segunda, desponta a participação de três brasileiros (alunos regulares) que frequentaram o Mestrado (lage Zendron Miola, Tiago de García Nunes e Lucas Pizzolato Konzen). Novamente, o trio tem raízes ligadas ao Rio Grande do Sul. No campo das revistas científicas, o IISL edita a Oñati Socio-Legal Series. Nela, a presença de autores brasileiros destaca-se com:

a) Daniel Achutti, no artigo publicado no volume 1 (2), 2011. Título: The Strangers in Criminal Procedure: Restorative Justice as a Possibility to Overcome the Simplicity of the Modern Paradigm of Criminal Justice.

b) José Augusto Fontoura Costa, no artigo publicado no volume 1 (4), 2011. Título: Comparing WTO Panelists and ICSID Arbitrators: the creaton of International Legal Fields.

c) Beltrina Côrte, no artigo no volume 1 (8), 2011. Título: La Comunicación como um derecho humano y su papel en la longevidade.

d) Thais Luiza Colaço, no artigo no volume 2 (3), 2012. Título: Existe responsabilidade corporativa ambiental de exploração econômica em terras indígenas no Brasil?

e) Zysman Neiman Hermann Hrdlicka, no artigo no volume 2 (3), 2012. Título: Responsabilidade socioambiental e o increment nas exportações brasileiras: um paradoxo.

São cinco artigos no total, um número razoável. Destaca-se, todavia, a preferência pelo uso das línguas latinas, em especial, a materna (Português). Revela-se novamente que o uso corrente do Inglês, o latim da ciência, em nível mundial, dificulta, em muito, uma maior inserção dos brasileiros nas publicações do IISL.

A Sortuz, por seu turno, é a revista editada e conduzida pelos estudantes e/ou por exestudantes do Mestrado. Nela, há apenas duas publicações de brasileiros: (a) Fernando Goya Maldonado (vol. 4, n2 - 2010) e (b) Germano Schwartz (2008). Ambos os trabalhos foram publicados em Inglês.

Verifica-se um dado importante em ambas as revistas. A partir de 2012, não se evidencia publicação de brasileiros, o que coincide com o uso mais rotineiro do sistema Qualis de avaliação dos periódicos, utilizado pelo Sistema Nacional de Pós-Graduação em Direito do Brasil. Seria, nesse sentido, altamente interessante que ambas as revistas se integrassem ao Qualis e com um bom score. 


\subsection{Bolsas}

O Instituto oferece, ainda, três possibilidades de bolsas. A saber:

\subsubsection{Bolsa de Residência}

Destinada a professores visitantes e/ou a pesquisadores que desejem acessar a Biblioteca ou o Centro de Documentação do IISJ por um determinado período de tempo. Ela disponibiliza hospedagem gratuita na Residência Antia em um quarto compartilhado. Seu tempo de duração máxima é de três meses.

Ademais, preferencialmente, o pesquisador deve pertencer ao grupo $C$ da tabela de classificação de países da International Sociological Association (ISA). Natural, portanto, que a concessão a brasileiros não seja significante, pois o país é posicionado na categoria $B$ da classificação mencionada. Mesmo assim, importante referir que dois brasileiros foram agraciados com a bolsa: Córa Hisao Higino e Martins Rennê.

\subsubsection{Pesquisadores e Professores Visitantes}

Muito semelhante à bolsa de Residência, a possibilidade de pesquisadores e professores visitantes terem acesso à Biblioteca do IISJ é facultada a essas pessoas. A diferença é que não se fornece a gratuidade na estadia (Residência Antia). Ela é paga, muito embora com um valor subvencionado. Sua concessão está sujeita à disponibilidade de espaço na Residência mencionada.

Nesse item, também se verifica uma significativa presença de brasileiros com base nos dados levantados a partir do ano de 2005. Supõe-se que o número de quarenta e um (41) apontado seja muito maior do que esse.

\subsubsection{Bolsa Juan Celaya}

Trata-se de bolsa destinada aos estudos relacionados ao Direito e ao fenômeno da globalização. Suas modalidades são: projetos de doutorado, colaboração internacional entre pesquisadores e projetos de pesquisa. Seu valor é de 6.000 euros, pagos da seguinte maneira: (a) 
20\% no momento da contratação; (b) $50 \%$ mediante relatório intermediário do pesquisador e (c) $30 \%$, no término do projeto.

Dois brasileiros foram contemplados com essa modalidade de bolsa:

a) Fábio de Sá e Silva: The World of Public Interest: How Globalization Works in the Everyday Lives of Advocates;

b) lagê Zendron Miola: Notables of law and economics: clashes and consensus between lawyers and economists in the import and practice of antitrust policy in Brazil (1994 - 2011).

\subsection{Biblioteca}

A biblioteca do Instituto Internacional de Sociologia Jurídica de Oñati é, certamente, a maior do mundo em sua área. Mas não é somente o critério quantitativo que a caracteriza, é o qualitativo. A excelência das obras que compõem o acervo vem acompanhada de sua variedade linguística.

Nesse sentido, registre-se que o Instituto possui quatro línguas oficiais (Euskera, Espanhol, Inglês e Francês), todas constantes do acervo da biblioteca. Além dessas, entre outros, são encontrados volumes escritos nos seguintes idiomas: alemão, italiano, português, albanês, árabe, búlgaro, catalão, chinês, croata, checo, dinamarquês, holandês, flamengo, eslovaco, estoniano, farsi, finlandês, galês, galego, georgiano, grego, hebreu, húngaro, islandês, indonésio, irlandês, japonês, coreano, latim, norueguês, polonês, português, romeno, russo, sueco e turco.

Talvez a maior conquista do acervo bibliotecário do Instituto tenha sido quando de sua criação. Fazer seu index constituiu um desafio que viabilizou traçar, ao final, um mapeamento completo dos assuntos e matérias relativas à Sociologia do Direito. Não se incorre em erro ao dizer que a Biblioteca é um dos grandes atrativos do IISL.

Nessa esteira, a presença de autores brasileiros nos itens do acervo pode ser verificada por meio de seu mecanismo de busca online. Dessa maneira, o levantamento abaixo adotou as seguintes expressões:
a) Língua: variável, como se verificará em seguida.
b) Origem: Brasil.
C) Itens: todos.
d) Data de Publicação: de 1800 a 2015. 
A partir desses parâmetros e não se escolhendo qualquer língua, chega-se a 1461 registros. Os autores mais encontrados são, na ordem: a) Eliane Botelho Junqueira (31); b) José Eduardo Faria (30); c) José Ribas Vieira (19); d) Germano Schwartz (13).

Usando-se o idioma português, os registros apontam o quantitativo de 618, e os autores de maior frequência são, na ordem: a) José Eduardo Faria (25); b) Eliane Botelho Junqueira (19); c) José Ribas Vieira (15); d) Rogério Gesta Leal (8).

Quando se utiliza o Inglês como a língua escolhida, são 449 os registros. Os autores mais frequentes são, na ordem: a) Eliane Botelho Junqueira (5); b) Edesio Fernandes (5); c) Germano Schwartz (5); d) Stephen Meili (4).

A partir do Espanhol, há 308 registros, e os autores mais encontrados são, na ordem: a) Miguel Pressburger (5); b) Jose Eduardo Faria (4); c) Eliane Botelho Junqueira (3); d) Wanda Capeller (3).

Na língua francesa, por seu turno, há 55 registros. A ordem dos autores, por frequência, é: a) Wanda Capeller (5); b) Eliane Botelho Junqueira (4); c) João Marcelo de Araujo Junior (3); d) Cláudia Fonseca (2).

Cumpre referir, ainda, que existem 19 registros em Italiano, sem grande frequência de um mesmo autor e que inexistem registros em Alemão.

Verifica-se, dos dados levantados, que a presença brasileira na biblioteca é incipiente e pouco internacionalizada. A frequência de registros do primeiro colocado em Português é seis vezes maior que a do primeiro posicionado em quaisquer das outras línguas, mesmo as latinas, revelando, portanto, que a carência maior se situa na produção brasileira em línguas diversas do Português.

\subsection{As Instâncias Diretivas: o Diretor Científico e o Patronato}

Em linhas gerais, o Diretor Científico responsabiliza-se pela condução das atividades acadêmicas do IISL, enquanto o Patronato é o órgão colegiado que toma as decisões estratégicas referentes à vida do Instituto, a maioria delas ligadas às atividades abordadas neste artigo, agregando-se os planos políticos e financeiros.

Até o presente momento, nenhum brasileiro ocupou cargo de Diretor Científico. A duração de seu mandato é de dois anos, e a remuneração é equivalente a de um professor titular na Espanha, além de acomodação gratuita na Residencia Antia. O RCSL aponta possibilidades de 
candidatos mediante edital publicado em sua newsletter. A decisão final da escolha para o cargo é do Patronato.

De outro lado, a composição do Patronato possui membros fixos ligados ao governo do País Vasco. Na mesma condição, faz parte do órgão o Diretor Científico. O Presidente do RCSL também é um posto natural. Três outros componentes são escolhidos pelo Presidente do RCSL entre seus membros. Nesse sentido, o único brasileiro a ocupar um posto no Patronato é Germano Schwartz (2014-2018) na qualidade de membro nomeado pelo Presidente do RCSL.

\section{CONCLUSÃO}

Tendo em vista os dados levantados pelo presente artigo, pode-se chegar a algumas considerações a respeito da participação dos brasileiros nas atividades típicas do Instituto Internacional de Sociologia Jurídica de Oñati. Ei-las:

a) O domínio do idioma Inglês evidencia um obstáculo para que os brasileiros lecionem no Mestrado. Outra questão é a falta de sincronia com o ano acadêmico brasileiro e a duração do Mestrado (Setembro-Março).

b) Dada à recente implementação da modalidade de pós-doutorado no IISL e a crescente demanda da realização do estágio pela CAPES e pelas Instituições Universitárias brasileiras, essa parece ser uma alternativa viável tanto para os brasileiros quanto para o Instituto em um futuro bastante próximo, desde que observadas as regras do Brasil sobre o tema.

c) O estímulo para alunos eventuais no Mestrado em Sociologia Jurídica pode ser algo a ser desenvolvido com uma política de revalidação de créditos entre mestrados brasileiros e o IISL, o que potencializaria o número de interessados do Brasil em face das regras pátrias, em relação ao reconhecimento de créditos realizados no exterior.

d) No que diz respeito aos alunos regulares, reforça-se que uma política de dupla titulação, tendo em vista as particularidades da regulação brasileira em educação de nível superior, seria algo que viabilizaria o recebimento de mais brasileiros. Aparentemente, assim como no caso dos alunos eventuais, o modelo do IISL é muito bem recebido no estado do Rio Grande do Sul, talvez pelo tipo de ensino jurídico ali desenvolvido, e, também, de certa forma, pela autorreprodução da excelência do Instituto entre seus ex-alunos. 
A PARTICIPAÇÃO DOS BRASILEIROS NO INSTITUTO INTERNACIONAL DE SOCIOLOGIA JURÍDICA DE OÑATI (1989-2015)

e) Em sendo a América Latina o maior contribuinte para alunos regulares do Mestrado em Sociologia Jurídica do IISL, não faz sentido que ele seja apenas o quarto país em envio de alunos nessa Região. É que o Brasil possui mais de mil e duzentas (1.200) Faculdades de Direito e em todas elas o ensino de Sociologia Jurídica é obrigatório (art. 5ª I, Resolução CNE/CES 09/04). Esse número de cursos jurídicos é menor na Argentina, no México e na Colômbia, países classificados à frente do Brasil. Tenha-se em mente que, em tais nações, o tema de Sociologia Jurídica não é obrigatório nas Faculdades de Direito. Há boas chances para o IISL no Brasil em termos de alunos regulares, portanto. O problema principal a ser enfrentado é a revalidação do diploma no Brasil. A oportunidade é a criação de uma dupla titulação.

f) Os workshops são o formato em que a presença de brasileiros melhor se distribui entre seus proponentes, muito embora exista uma concentração em certos nomes, e, também, uma tendência no novo milênio de que esses organizadores sejam oriundos do Rio Grande do Sul. Ainda, a organização de workshops em Espanhol é uma tendência que se explica pelo fato de o Inglês não ser uma língua corrente entre os acadêmicos de Direito do Brasil, enquanto o Espanhol, uma língua latina, guarda mais semelhança com o Português.

g) No que concerne às publicações, é impossível deixar de registar que, em apenas uma oportunidade, os organizadores brasileiros dos workshops utilizaram as séries patrocinadas pelo IISL para escoar as discussões realizadas em Oñati. Como nenhuma das séries publicadas ou por Hart ou por Dickynson aceitam a publicação em Português, o domínio do idioma (Inglês/Português) parece impedir a consecução dessa alternativa. 0 mesmo argumento é válido para as revistas (Oñati Socio-Legal e Sortuz), com a ressalva de que é necessária a integração de ambas ao sistema Qualis-Capes brasileiro.

h) Os brasileiros são agraciados com uma boa quantidade de bolsas, em especial - e notadamente -, para o uso da biblioteca, na modalidade de pesquisadores e professores visitantes que pagam pelo uso da Residência.

i) A presença de autores brasileiros na biblioteca é incipiente, pois ainda se prende muito mais ao idioma Português. Leve-se em consideração que essa não é uma língua oficial do IISL e se evidencia o porquê dos sociólogos do Direito do Brasil não figurarem, mais vezes, nos registros da biblioteca.

j) Os cargos diretivos raramente são ocupados por brasileiros. 0 posto de Diretor Científico possui uma remuneração, na maioria das vezes, menor do que o padrão brasileiro para posições semelhantes e exige que o candidato viva dois anos na Espanha. Isso é bastante difícil para acadêmicos que estejam na ativa, pois o Brasil, com raras exceções, não contempla a 
possibilidade do sabático. Na mesma linha, participar do Patronato exige participação regular - e legitimidade - perante o RCSL, o que não tem sido regra para os acadêmicos brasileiros.

\section{REFERÊNCIAS}

ARRESE MURGUZUR, Susana; PÉREZ-PERDOMO, Rogelio. El Máster de Sociología Jurídica de Oñati: la Percepción de los Graduados (The Oñati Master on Sociology of Law: the Alumnae's Perception). Oñati Socio-Legal Series, Vol. 6, No. 3, 2016. Disponível em: <http://ssrn.com/abstract=2676532> Acesso em 03 abr. 2017.

FARIA, José Eduardo; CAMPILONGO, Celso Fernandes. A Sociologia Jurídica no Brasil. Porto Alegre: SAFE, 1991.

FRAGALE FILHO, Roberto; ALVIM, Joaquim Leonel de Rezende. O Movimento “Critique du Droit"e seu Impacto no Brasil. Revista Direito GV, v.3, n.2, jul-dez 2007, p. 139-164. Disponível em: <http://bibliotecadigital.fgv.br/ojs/index.php/revdireitogv/article/view/35186/33990> Acesso em: 03 abr. 2017.

JUNQUEIRA, Eliane Botelho; OLIVEIRA, Luciano (Org). Ou Isto ou Aquilo: a sociologia jurídica nas Faculdades de Direito. Rio de Janeiro: Letra Capital, 2002.

PODGORECKI, Adam. Goals of the RC12. 1996. P. 1-10. PDF Oñati.

PODGORECKI, Adam. The Changing Philosophy of the Research Committee of Sociology of Law (ISA). 1989. P. 12-29. PDF Oñati.

SOUTO, Cláudio. Sobre a Pesquisa Científica em Direito. Revista Brasileira de Sociologia do Direito, v.1, n.1, 2014, p. 38-40. Disponível em:

<http://dx.doi.org/10.21910/rbsd.v1n1.2014.35> Acesso em: 03 abr. 2017.

TABAK, Fanny (Ed). The Implementation of Equal Rights for Men and Women. Oñati Proceedings. Institute International for the Sociology of Law: Oñati, 1991.

Recebido em: 27/04/2016 / Revisões requeridas em: 22/09/2016 / Aprovado em: 18/01/2017 